more than two hundred, ranged over pure and applied mathematics, logic, philosophy, grammar, comparative philology, international languages, and even politics. Some early papers dealt with the algebra of invariants. $\mathrm{He}$ then turned to calculus and differential equations. His 'space-filling curve' has been described as one of the most remarkable results in the theory of aggregates. The investigations of the foundations of geometry and arithmetic are of great importance, but his crowning achievement is his system of mathematical logic, with its elaborate symbolism (the 'Peanese' ridiculed by Poincaré), which has been used in England by Russell and Whitehead. Peano applied his logical methods to grammar, and this led to other linguistic studies, including the invention of the international language Interlingua. As a contrast to his abstract work may be mentioned his methods for the approximate solution of problems in practical mathematics. He stands out in the history of science as one of the few modern thinkers who have combined profound originality with a wide range of activities.

\section{The Indian Mathematical Society}

THE jubilee commemoration volume of the Journal of this Society contains, in addition to the usual research papers, an account of the history of the Society. It began in a very modest way in 1907, when Mr. V. Ramaswamy Aiyyar, then deputy collector at Grooty, formed the "Analytical Club", the object of which was to subscribe for mathematical periodicals and circulate them among the members. In 1909 appeared the first number of the Journal. By the end of 1910, the name of the Society had changed twice, first to the "Indian Analytical Club" and then to the "Indian Mathematical Society". The number of members, originally about twenty, is now nearly three hundred. A central library is maintained at Poona, and conferences are held biennially in different parts of India. The Society is conducting an inquiry into the present conditions of mathematical teaching and examinations in schools and colleges, with the view of introducing certain reforms, and is also trying to set up prizes for research. It is considering the advisability of dividing its Journal into two parts, an advanced part for the publication of research papers, as at present, and a new elementary part, similar to the Mathematical Gazette or the American Mathematical Monthly. The achievement of which the Society is most proud is the discovery of the great Indian mathematician Ramanujan, whose contributions began to appear in the Journal in 1911. In the present volume, the place of honour is given to two papers developing Ramanujan's results.

\section{The Automatic Telephone}

WE think that an elementary knowledge of automatic telephony is almost a necessity to every welleducated young man. We therefore welcome the brief description in pamphlet form of the processes involved in making a call on the automatic systems of the British Post Office. It forms an excellent supplement to the demonstrations given daily on the automatic telephone equipment installed at the Science Museum by the Post Office. The various ways in which a call can be made are described and illustrated by four simple diagrams. It is possible with the aid of the pamphlet to understand the main features of automatic telephony without going too deeply into technicalities and manufacturing expedients. The pamphlet (price 6d.) is published by H.M. Stationery Office, and is useful for reference.

\section{Regulations for the Electrical Equipment of Buildings}

The Institution of Electrical Engineers has just published the tenth edition of its regulations for the wiring of buildings. The ninth and preceding editions were entitled the "I.E.E. Wiring Rules". This publication is very opportune, for the wide use of luminous discharge tubes and 'all electric' receiving sets has introduced several new problems as to the necessary requirements and precautions required for ensuring satisfactory results and providing immunity from fire and shock. The regulations do not take the place of a detailed specification but are supplementary to it. We think that any wiring system which complies with the instructions laid down in this little book (price ls.) will be found satisfactory. The Wiring Regulations Committee has obviously taken great pains in its preparation. The definitions of the technical terms used are clear and the instructions for testing the completed installation are very good.

\section{Congress of Anthropological and Ethnological Sciences}

THE September issue of Man is devoted to the first session of the International Congress of Anthropological and Ethnological Sciences which was held in London on July 30-August 4. A group photograph in three sections of the members of the Congress forms the frontispiece of the issue, and a general survey by Prof. J. L. Myres, one of the general secretaries, opens the report. Full summaries are given of Lord Onslow's presidential address on "Anthropology in Administration" and of the Huxley Memorial Lecture by Sir Aurel Stein, as well as of the evening discourses delivered by Prof. T. C. Hodson on the census of India, by Dr. R. R. Marett on the tendency of anthropological studies and by Prof. J. B. S. Haldane on "Anthropology and Human Biology". The proceedings in each of the eleven sections among which the work of the Congress was distributed are briefly reported either by the sectional president or the secretary. As some delay is inevitable before the volume containing the full account of the proceedings with abstracts, etc., is available, this very full report is not only welcome, but also will be extremely useful for purposes of reference until a more authoritative source is available.

\section{Boots Pure Drug Company's Medical Products}

Messrs. Boots Pure Drug Co., Ltd., Nottingham, have issued a small booklet about the therapeutic uses of medicinal glucose or anhydrous dextrose. Glucose is usually given by mouth but may be administered by rectum or intravenously. Its great advantage over other forms of carbohydrate in the 
diet is that it is absorbed without change and so provides an easily assimilable foodstuff. The list of indications for glucose therapy is lengthy, including acute infections, conditions of malnutrition and more specifically hepatic toxæmias and insulin hypoglycæmia. The gonococcus vaccines issued by Messrs. Boots Pure Drug Co., Ltd., are prepared in the Department for Venereal Diseases at St. Thomas's Hospital, London. Three types of vaccine are available-a simple emulsion of gonococci, a detoxicated vaccine, making it possible to inject with safety a considerably larger dose, and also a mixed vaccine of gonococei with streptococci, staphylococci, diphtheroids and coliform bacilli, organisms commonly found in gonorrhœa complicated by secondary infection. The organisms in all vaccines are killed by the addition of 0.5 per cent phenol. The vaccines appear to be of distinct value in the treatment of all gonococcal infections, although it may be advisable to defer their use until the acute symptoms of urethritis have subsided. The number of organism 3 in the vaccines ranges from 200 to 10,000 million per c.c.

\section{Announcements}

The Council of the Institution of Civil Engineers has made the following awards: Baker Gold Medal to Ralph Freeman (London). For papers read and discussed at ordinary meetings : Telford Gold Medals to Dr. J. J. C. Bradfield (Sydney, Australia) and to Ralph Freeman (London); Webb Prize and Telford Premium to W. E. Gelson (Delhi) ; Indian Premium to J. D. Watson (Lahore); Telford Premium jointly to Ralph Freeman (London) and Lawrence Ennis (London); Telford Premium jointly to E. F. Law (London) and Vernon Harbord (London); Manby Premium jointly to J. F. Pain (Winchester) and Gilbert Roberts (Margate); Trevithick Premium jointly to R. W. Foxlee (London) and E. H. Greet (Iver, Bucks.). For papers published without discussion as "Selected Engineering Papers": Telford Premiums to E. F. Reid (London); jointly to F. W. H. Stileman (Weybridge, Surrey) and J. S. Young (Perth, Australia); to E. H. Bateman (Birmingham); to A. C. Gardner (Glasgow); to W. G. Morrison (London); to B. C. Hammond (Worcester); Crampton Prize to G. M. T. Rees (Gerrards Cross, Bucks.). The Charles Hawksley Prize has been awarded to H. G. Cousins (London) and the Coopers Hill War Memorial Prize to F. V. Appleby (Brighton).

The Carnegie Institution of Washington, Washington, D.C., has issued its annual catalogue of publications (pp. xlv +131). A few copies of each publication are reserved for sale at prices below printing cost, and price lists or classified lists may be obtained upon request.

The National Council of Social Service would be very grateful for gifts of second-hand microscopes and telescopes. There are four training centres at which selected unemployed men are instructed in subjects which can be carried on in the Clubs to which they belong. There is a strong desire for instruction in scientific subjects and there are no funds wherewith to buy the instruments. Gifts should be sent to the Secretary, National Council of Social Service, 26 Bedford Square, W.C.1.

A SERIES of 'class' catalogues of the books in the Library, including the Departmental Libraries, of the London School of Hygiene and Tropical Medicine, Keppel Street, London, W.C.1, is in course of preparation, the first of which has just been issued. This contains the books in Class B (Natural Science). University theses are included, but not periodical publications and pamphlets. The works are classified under subject headings which in many cases are duplicated, and are arranged chronologically by date of publication. The entries are abbreviated to the barest essentials, and an alphabetical index to the subjects represented in Class B is appended. The work will be sent gratis upon request to the Librarian.

Messrs. Hutchinson's Technical and Scientific Book Co. are publishing a new "Technical and Scientific Encyclopædia" under the editorship of Messrs. C. F. Tweney and I. P. Shirshov. It is being issued in about forty weekly parts (1s. 6d. a part); and Part 1, which has just appeared, contains 48 double-column pages. The type is small but clear, the headings stand out plainly, and many of the short descriptive articles are accompanied by useful diagrams. It is proposed to cover the whole field of science as it is applied in industry. The editors have secured the services of a very competent panel of contributors, each of whom deals with his own particular subject. A list of standard books and papers on each subject is promised in the concluding parts.

Applications are invited for the following appointments, on or before the dates mentioned :-An instructor in the Department of Mechanical Engineering, Leeds College of Technology-The Director of Education, Education Offices, Leeds (Oct. 15). An executive engineer in the United Provinces Service of Engineers (Irrigation (Hydroelectric) Branch) - The High Commissioner for India, General Department, India House, Aldwych, London, W.C.2 (Oct. 20). A lecturer in veterinary hygiene at the East Anglian Institute of Agriculture, ChelmsfordThe Clerk of the Council, County Hall, Chelmsford (Oct. 24). A principal and head master of the Gravesend Technical Institute and Junior Technical School-Mr. W. A. Clench, Bank Chambers, Windmill Street, Gravesend (Oct. 27). A lecturer in biology at the Warrington Training College, Wavertrec, Liverpool, 16-The Principal. An assistant conservator of the museum of the Royal College of Surgeons of England, Lincoln's Inn Fields, W.C.2-The Secretary (Nov. 8). Research workers to take charge of nutritional research under the Indian Research Fund Association at Coonoor-The High Commissioner for India, India House, Aldwych, London, W.C.2 (Nov. 30). A water and drainage engineer for the Simla Municipality-The Secretary, Municipality, Simla, India (Dec. 10). An assistant for work in connexion with research in aeronautic instruments in the Directorate of Scientific Research, Air Ministry-The Chief Superintendent, Royal Aircraft Establishment, South Farnborough, Hants. 